\title{
Rosabetty Muñoz. En Nombre de Ninguna
}

Valdivia: Ediciones Kultrún, 2008. 33 pp.

Rosabetty Muñoz (1960) es una poeta chilena que presenta una trayectoria reconocida en el país, al haber sido estudiada y antologada por críticos e investigadores de renombre. Ha recibido el premio Pablo Neruda (2000), el premio Consejo Nacional del Libro (2002) y la reciente nominación al premio de las artes nacionales "Altazor" (2009). Autora de Canto de una oveja del rebaño (1981), En lugar de morir (1987) Hijos (1991), Baile de señoritas (1994), La Santa. Historia de su elevación (1998), Todas en mí (2000), Sombras en el Rosselot (2002), Ratada (2005) y En nombre de Ninguna (2008).

El principal estudioso de la poesía de Rosabetty Muñoz, Iván Carrasco, ha señalado que sus textos son un aporte a la poesía nacional, al presentar variaciones significativas con otros poetas de su generación, permitir diversas lecturas, incorporar elementos interculturales y explorar aspectos negados de la identidad cultural. Estos aspectos negados en las identidades culturales del país son, según Oscar Galindo y Sergio Mansilla, el territorio sureño que se configura como anti-paraíso y, según Carrasco, la realidad que se perfila como devastada por la crueldad y la historia, que se origina en el cruce conflictivo entre sociedades de culturas diferentes al remarcar aspectos como la discriminación, la exclusión, etc. Esta representación de la realidad y configuración de la identidad que caracterizan la poesía de Rosabetty Muñoz permanecen en su última publicación, aunque dejan de ser representativas de una localidad determinada, el sur de Chile, e introducen problemáticas propias de la existencia humana en general, como la pérdida y el duelo.

En Nombre de Ninguna es un texto novedoso al utilizar variadas estrategias textuales e icónicas. Presenta un segundo título, “Álbum Familiar”, que incluye dos secciones nominadas "[muñecas]"y "La Sombra de la Hija”. Está escrito en verso libre y reúne poemas en prosa en la primera sección y poemas estróficos en la segunda. Además, el libro presenta elementos que sugieren un álbum fotográfico antiguo: cada texto representa una fotografía con un borde exterior o marco e incluye una página en blanco que separa las páginas. Los signos icónicos que presenta son la fotografía de una bolsa de basura cerrada en la cubierta delantera, una figura religiosa antigua en la contratapa y el pequeño dibujo de un ángel al centro de cada página.

En Nombre de Ninguna es también un texto original al introducir la dimensión de lo religioso y reconsiderar elementos populares entendidos como sagrados en el país. Por ello, presenta relaciones transtextuales con la Biblia, la canción popular y estrategias como los paratextos (epígrafe, segundo título, subtítulos) centrados en la religión católica.

Otros aspectos literarios que hacen de En Nombre de Ninguna un texto interesante es presentar un discurso transgresor de la realidad donde el mundo representado reúne la ilegalidad y la supervivencia. Esta dimensión aparece en el texto en las figuras de la maternidad y la filiación que configuran hablantes como la mujer que aborta y el hijo perdido. 
La pérdida es una noción central en la poesía de la autora, que representa una realidad siempre en falta, devastada. La pérdida se presenta en la enunciación que asume la forma de diversas identidades representadas por sujetos desligados o distantes de su origen familiar y / o cultural: todos los hablantes han perdido el nexo con la historia y la memoria que los liga a lazos sociales de parentesco y de la comunidad. Una de las formas de representar la pérdida del origen es la ausencia de nominación. No solo el hijo ha sido desprovisto de identidad al ser privado de un nombre, sino también la madre es inidentificable o identificada como "ninguna" al haber perdido tanto a aquél que estuvo en su cuerpo como a la maternidad como proyecto.

Sin embargo, En Nombre de Ninguna presenta la polifonía como mecanismo que permite no solo presentar la pérdida, sino también realizar un duelo entendido como bautismo religioso e inscripción de un nombre. El duelo surge como la necesidad humana de consumar un ritual ante la muerte, que consiste en la escritura del nombre del que ha muerto como signo de vida análogo al bautismo que permite la resurrección. El nombre no solo tendrá el sentido de hacer existir, sino de otorgar la posibilidad de recordar al ausente mediante su nombre, como aquél que fue o la identidad que tuvo. De esta forma, el nombre promueve el duelo compartido por una comunidad o lo legaliza en la cultura. El duelo vincula comunidad y religión, en la figura del bautismo religioso entendido como la inscripción del nombre ligado a la familia. En el texto se presenta una noción diversa de familia ligada al sentimiento de filiación a una comunidad. La muerte es sentida como la muerte de un hijo por pertenecer a la comunidad y la nominación de un miembro muerto no reconocido, no solo permite renacer como hijo de Dios sino también como mujer - madre sustituta y miembro de una comunidad. La nominación es una condición de existencia y crea una historia personal y familiar que perpetúa la memoria de una comunidad.

En Nombre de Ninguna tiene el valor de producir nuevos significados y significantes en las voces que se enfrentan a la pérdida. Lo perdido es la ausencia de un nombre tanto como expresión de un deseo que permita asumir la identidad de madre como de hijo e integrante de una comunidad. La pérdida tiene como discurso de fondo elementos que la cultura niega como la maternidad identificada al castigo, el aborto, el incesto, la ausencia del padre y el maltrato a los hijos desde la infancia. Otras formas de representar la pérdida son en la desvitalización, la violencia y la transgresión. En la desvitalización el retrato fotográfico de familia entendido como lenguaje adquiere una función análoga al nombre propio y permite la manifestación del poliglotismo entre diversos lenguajes, como la popular oral y la fotografía. La violencia y transgresión surgen a propósito de la representación de la sexualidad y la corporalidad femenina.

El texto permite denunciar y promover un duelo por un discurso que la cultura no transmite respecto a la maternidad. La imposibilidad de ser madre está mediada por factores ideológicos que impiden que este proyecto sea realizado o que niegan aspectos trascendentes de la maternidad. Además, produce una nueva realidad: la figura de la madre que pierde o adopta son identidades posibles que la voz principal dispone para presentar la pérdida y la desvinculación de nuestra cultura con su propio origen y memoria. 
El principal mérito de En Nombre de Ninguna consiste en reconfigurar las dimensiones de la vida y la muerte como proyectos que siempre son enigmáticos para la humanidad y presenta el sentido del perdón como un ritual estético: mediante la entrega de un don, el texto poético que se presenta como un sentido nuevo para la vida.

Paula Tesche

Universidad Austral de Chile Doctorado en Ciencias Humanas paulatesche@yahoo.com 